\title{
ESTUDO E AVALIAÇÃO DAS PROPRIEDADES DE ARGILAS UTILIZADAS NA INDÚSTRIA DE CERÂMICA VERMELHA DA REGIÃO DO CARIRI- CEARÁ*
}

\author{
Amélia de Santana Cartaxo ${ }^{1}$ \\ Antônio Demouthie de Sales Rolim Esmeraldo² \\ Philipe Macêdo Suassuna ${ }^{3}$ \\ Ana Cândida Almeida Prado 4 \\ Laédna Souto Neiva \\ Maria Isabel Brasileiro
}

\section{Resumo}

O objetivo desta pesquisa é caracterizar matérias-primas, massas e produto final, de indústrias da cerâmica vermelha presentes na região do cariri - $C E$, e que ainda não tenha suporte técnico para melhorar seus produtos ou até adequá-los as Normas Técnicas vigentes. Inicialmente, foram utilizados quatro tipos de argilas provenientes da Indústria Cerâmica Pé Seco, localizada na cidade do Crato na Região do CaririCeará. Estas argilas foram submetidas aos ensaios de plasticidade pelo Método Atterberg, em seguida foram queimadas em três temperaturas diferentes $\left(700^{\circ} \mathrm{C}\right.$, $850^{\circ} \mathrm{C}$ e $1.050^{\circ} \mathrm{C}$ ) e avaliadas o comportamento de absorção de água, retração linear, perda ao fogo e a tensão de ruptura à flexão.Todas as amostras de argila obtiveram um aumento da perda ao fogo, tensão de ruptura e retração linear com o aumento da temperatura, entretanto houve redução da absorção de água. De acordo com o teste de plasticidade, apenas as amostras AV, AB1e BP apresentaram plasticidade dentro do recomendado.

Palavras-chave: Caracterização; Argila; Cerâmica vermelha.

\section{STUDY AND EVALUATION OF PROPERTIES OF CLAY USED IN THE INDUSTRY OF RED CERAMIC FROM REGION CARIRI- CEARÁ}

\section{Abstract}

The objective of this research is to characterize raw materials, pasta and final product of the ceramic industries in the region of cariri - CE, and which has not technical support to improve their products or to adapt them to the Technical Standards. Initially, was used four types of clay from the Industry Ceramic Pé Seco, located in Crato city in Region Cariri- Ceará. These clays were submitted to the plasticity tests by Atterberg, method, and then sintering at three different temperatures $\left(700^{\circ} \mathrm{C}, 850^{\circ} \mathrm{C}\right.$ and $\left.1,050^{\circ} \mathrm{C}\right)$ and evaluated the water absorption behavior, linear shrinkage, loss on ignition and the Flexion Rupture Tension. All samples clay had an increased loss on ignition, Rupture Tension, and linear shrinkage with temperature increase, however happened a reduction in water absorption. According to the plasticity test, only the AV, AB1 and BP samples presented in the plasticity recommended.

Keywords: Clay; Evalution; Red ceramic.

1 Graduando no curso de Engenharia de Materiais, titulação, bolsista, Departamento de Engenharia de Materiais, Universidade Federal do Cariri, Juazeiro do Norte, Ceará, Brasil.

2 Graduando no curso de Engenharia de Materiais, titulação, bolsista voluntário, Departamento de Engenharia de Materiais, Universidade Federal do Cariri, Juazeiro do Norte, Ceará, Brasil.

3 Graduando no curso de Engenharia de Materiais, titulação, bolsista, Departamento de Engenharia de Materiais, Universidade Federal do Cariri, Juazeiro do Norte, Ceará, Brasil.

4 Engenheira de Materiais, Doutora, professora, Departamento de Engenharia de Materiais, Universidade Federal do Cariri, Juazeiro do Norte, Ceará, Brasil. 


\section{INTRODUÇÃO}

No estado do Ceará, existem aproximadamente, 254 fábricas de produtos de cerâmica vermelha funcionando, distribuídas na sua maioria em pelo menos 10 municípios, ofertando cerca de 8.000 empregos diretos e 30.000 indiretos FIEC [1]. $\mathrm{Na}$ região do Cariri, esse número chega a aproximadamente 30 empresas, sendo estas indústrias de minerais não-metálicos, caracterizada como uma indústria "nativa" da Região, tendo uma estrutura de gestão marcadamente familiar, onde a presença das micro e pequenas olarias ainda é importante MEHISUFC [2].

Apesar da grande importância socioeconômica, muitas indústrias de cerâmica vermelha da região, ainda possui um grande atraso tecnológico em relação ao controle do processo industrial. Desde a preparação da matéria-prima, com 0 desconhecimento das características das argilas, até o produto final, no qual muitas vezes não se encontra enquadrado dentro das Normas, essas indústrias têm fabricado produtos de má qualidade além de obter grandes perdas durante o processamento. A execução do processo, na maioria das fábricas da região, se caracteriza pela sua simplicidade, em que é feita a mistura de dois tipos de argila com água. Essa mistura é conformada em uma extrusora, seguida por secagem ao ar livre e posteriormente queima.

Portanto, este trabalho teve como objetivo a caracterização físico-mecânica das argilas utilizadas na indústria cerâmica Pé Seco situada na cidade do Crato- região do Cariri- Ceará, avaliando as propriedades das argilas utilizadas e indicando uma possível melhora, se for o caso, no processamento dos produtos afim de obtê-los com características eficazes e que se enquadrem dentro das normas técnicas.

\section{MATERIAIS E MÉTODOS}

Foram coletadas quatro amostras provenientes da indústria de Cerâmica vermelha Pé Seco, localizada no município de Crato, na região metropolitana do Cariri. Estas matérias-primas coletadas receberam as seguintes nomenclaturas: Argila Branca 1, Argila Branca 2, Argila Verde e Barro Preto.

Primeiramente, o material coletado foi submetido a um beneficiamento, o qual consistiu em secagem em estufa a $110^{\circ} \mathrm{C}\left( \pm 10^{\circ} \mathrm{C}\right)$ por 24 horas e em seguida moagem em moinho martelo da marca SERVITECH. Após esse beneficiamento, as amostras foram ensacadas e enumeradas de acordo com seus respectivos nomes: AB1(Argila Branca 1), AB2(Argila Branca 2), AV (Argila Verde) e BPps (Barro Preto Pé Seco). Para a análise do índice de plasticidade, realizou-se o peneiramento em malha ABNT número $40(0,42 \mathrm{~mm})$ e o método empregado nessa determinação foi 0 Atterberg. Assim, pode-se calcular limite de plasticidade, o limite de liquidez e o índice de plasticidade segundo as NBR's 6459 [3] e 7180 [4]. A umidade em cada ponto foi calculada por:

$$
\mathrm{H}(\%)=[(\mathrm{P} 1-\mathrm{P} 2) /(\mathrm{P} 2-\mathrm{P})] * 100
$$

Onde $\mathrm{P} 1$ é a massa úmida, $\mathrm{P} 2$ é a massa seca e $\mathrm{P}$ é a massa do recipiente. O limite de liquidez foi determinado através do aparelho Casagrande e calculado pela equação (2), da American Society for Testing Materials. Essa equação é utilizada no caso de não se conseguir obter a condição estipulada pelo método para as 25 pancadas. 
$\mathrm{WN}=$ percentagem de umidade correspondente a $\mathrm{N}$ pancadas.

$\mathrm{N}=0$ número de pancadas da determinação.

Para o limite de plasticidade (LP), ao se fragmentar o cilindro, imediatamente seus pedaços foram colocados em um recipiente e a umidade foi determinada pela Equação (1). Essas operações foram reproduzidas até que três valores obtidos ficaram no intervalo de $5 \%$ da média. Então o limite de plasticidade foi expresso pela média dos teores de umidade obtidos como indicado acima, aproximando-se para o número inteiro mais próximo. Diante disso, o índice de plasticidade (IP) foi calculado pela subtração entre os limites de liquidez e de plasticidade, a partir da Equação (3), para cada uma das argilas.

$$
I P=L L-L P(3)
$$

Em seguida, os corpos-de-prova foram inseridos dentro de uma estufa com temperatura de $110 \pm 10^{\circ} \mathrm{C}$ para determinar a umidade que foi adicionada para a obtenção dos corpos-de-prova e determinar o índice de plasticidade de Atterberg. Esta umidade foi medida de acordo com a equação 1.

Para os corpos de prova, pesou-se cerca de $500 \mathrm{~g}$ de cada argila. Foram adicionados $8 \%$ do peso de água homogeneizando-as e passando o material em malha de 30 mesh duas vezes. Após isso, o corpo de prova foi prensado uniaxialmente com uma carga de 4ton. Foram prensados 15 corpos de prova de cada argila, enumerados em uma das extremidades de 1 a 15 e medidas as dimensões de largura, comprimento e espessura dos mesmos com auxílio de um paquímetro. Em seguida, foi colocado em uma estufa a $110^{\circ} \mathrm{C}$ por 24 horas, para secagem, cada corpo-de-prova foi pesado e os valores anotados.

Os corpos foram divididos em três grupos e queimados nas temperaturas de $700^{\circ} \mathrm{C}$, $950^{\circ} \mathrm{C}$ e $1050^{\circ} \mathrm{C}$. Após as queimas, os corpos de prova foram pesados e novamente tiveram suas dimensões medidas com o auxílio de um paquímetro. Os valores da retração linear de queima foram calculados de acordo com a Equação (4).

$$
\Delta L=\frac{L_{0}-L_{f}}{L_{0}} * 100(4)
$$

Onde, $L_{0}$ e $L_{f}$ são as medidas dos comprimentos antes e após a queima, respectivamente. A perda ao fogo (PF) foi calculada de acordo com a Equação (5):

$$
P F=\frac{P_{0}-P_{f}}{P_{0}} * 100
$$

Onde, $\mathrm{P}_{0}$ e $\mathrm{P}_{f}$ são as medidas do peso antes e depois da queima, respectivamente.

Para o ensaio de flexão, foi utilizada a máquina do modelo Flexi 1000 LX-650 da marca Gabbrielli, satisfazendo as condições de exigência. A distância dos apoios foi determinada em 59,3 mm. Após o rompimento, a carga aplicada e as medidas de largura e espessura da região de rompimento do corpo de prova, foram anotadas. $\mathrm{O}$ cálculo da tensão de ruptura (TR) foi obtido mediante a utilização da Equação 6:

$$
T R=\frac{3 Q d}{2 * L * E^{2}}(6)
$$


Onde, $Q$ é a carga aplicada no ensaio, d é a distância entre os apoios, $L$ e $E$ são a largura e espessura do corpo de prova na região da ruptura, respectivamente.

Uma das partes rompidas das amostras, após o ensaio de flexão, foi colocada em água, permanecendo por $24 \mathrm{~h}$ e calculou-se o valor do Peso úmido (Pu). A absorção de água (AA) foi encontrada pela Equação 7:

$$
A A=\frac{M_{u}-M_{s}}{M_{s}} * 100
$$

Em que, Mu é a massa do pedaço da amostra que ficou dentro da água por pelo menos $24 \mathrm{~h}$ e Ms é o valor da massa do pedaço da amostra quebrada após o ensaio de flexão.

\section{RESULTADOS E DISCUSSÃO}

Os resultados para os limites de liquidez, de plasticidade e os índices de plasticidade obtidos pelo método Casagrande, estão apresentados na Tabela 1.

Tabela 1 - Limite de Liquidez, Limite de Plasticidade e Índice de Plasticidade das argilas estudadas.

\begin{tabular}{cccc}
\hline Amostra & Limite de Liquidez & Limite de Plasticidade & Índice de Plasticidade \\
\hline AV & $63,4 \%$ & $33,06 \%$ & $30,4 \%$ \\
\hline BPps & $23,7 \%$ & $8,32 \%$ & $15,4 \%$ \\
\hline AB1 & $58,8 \%$ & $27,3 \%$ & $31,6 \%$ \\
\hline AB2 & $37,1 \%$ & $23,3 \%$ & $8,9 \%$ \\
\hline
\end{tabular}

Observou-se que o limite de liquidez variou de 23,7\% a 63,4\%. De acordo com Macedo [5,6] estão inclusas no intervalo do limite de liquidez. Quanto ao índice de plasticidade, os valores variaram entre 8,9\% a 31,6\%. De acordo com Macedo [7], a amostra $\mathrm{AB} 2$ foi classificada com plasticidade mediana, pois possui índice de plasticidade entre 7 e 15, e as amostras AV, AB1 e BPps foram classificadas com alta plasticidade pois apresentaram índice de Plasticidade maior que $15 \%$. Os valores obtidos estão dentro da faixa para o índice de plasticidade para argilas utilizadas na cerâmica vermelha segundo Macedo [6], exceto a amostra AB2. O limite de plasticidade variou-se de $8,32 \%$ a $33,06 \%$, os quais segundo Macedo [6] apenas as amostras $A V, A B 1, A B 2$ estão dentro da faixa para esse parâmetro.

A figura 1 apresenta os valores de retração linear das amostras para três temperaturas diferentes. Com base na tabela, percebe-se um aumento da retração linear com o aumento da temperatura. Isso acontece devido à densificação, decorrente do processo de sinterização, como era esperado. A argila AB2, apresentou a menor retração linear de todas, devido provavelmente ao maior teor de $\mathrm{SiO}_{2}$, o qual diminui a plasticidade dessa argila melhorando a permeabilidade e a estabilidade dimensional dos corpos de prova Cartaxo [8]. A argila AB1 apresentou os maiores valores de retração linear. 


\section{RETRAÇÃO LINEAR}

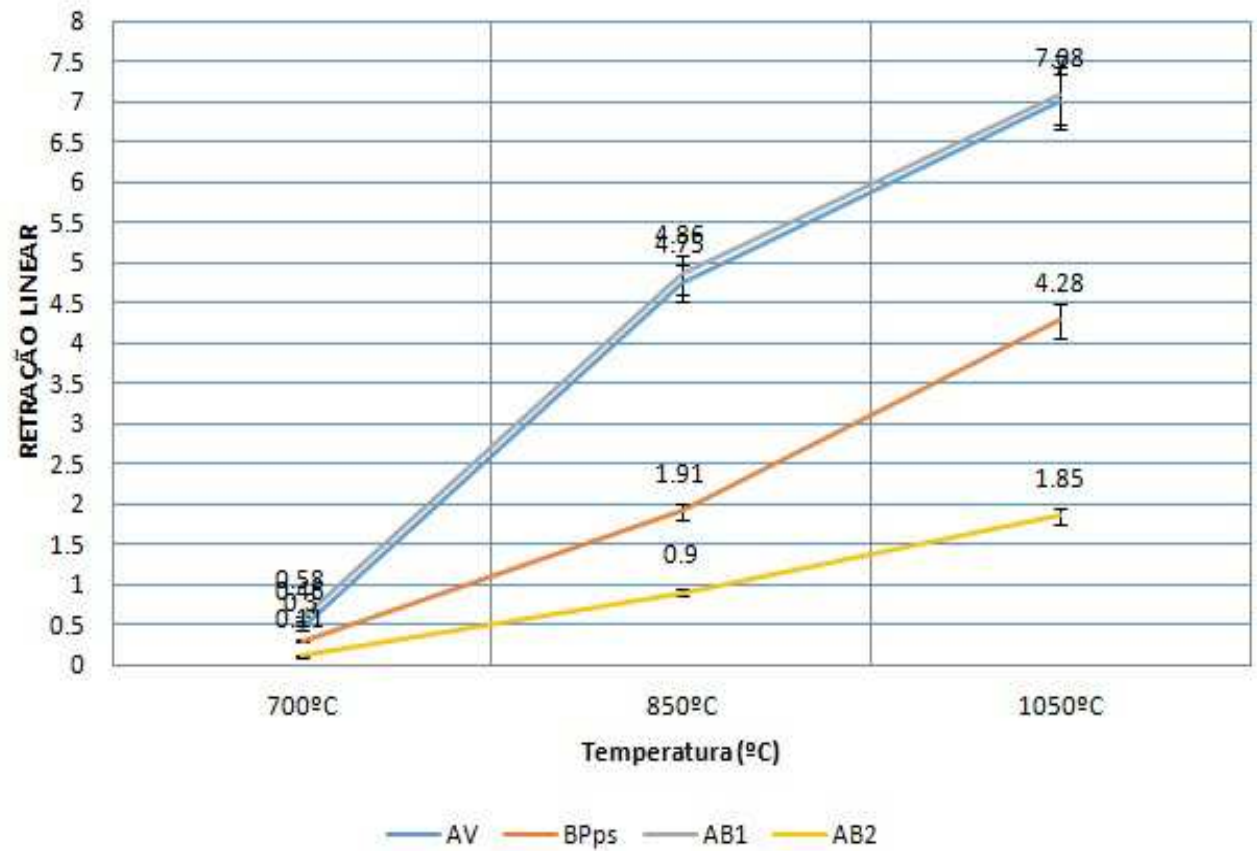

Figura 1.Gráfico de Retração Linear dos corpos-de-prova após queima.

\section{ABSORÇÃODE ÁGUA}

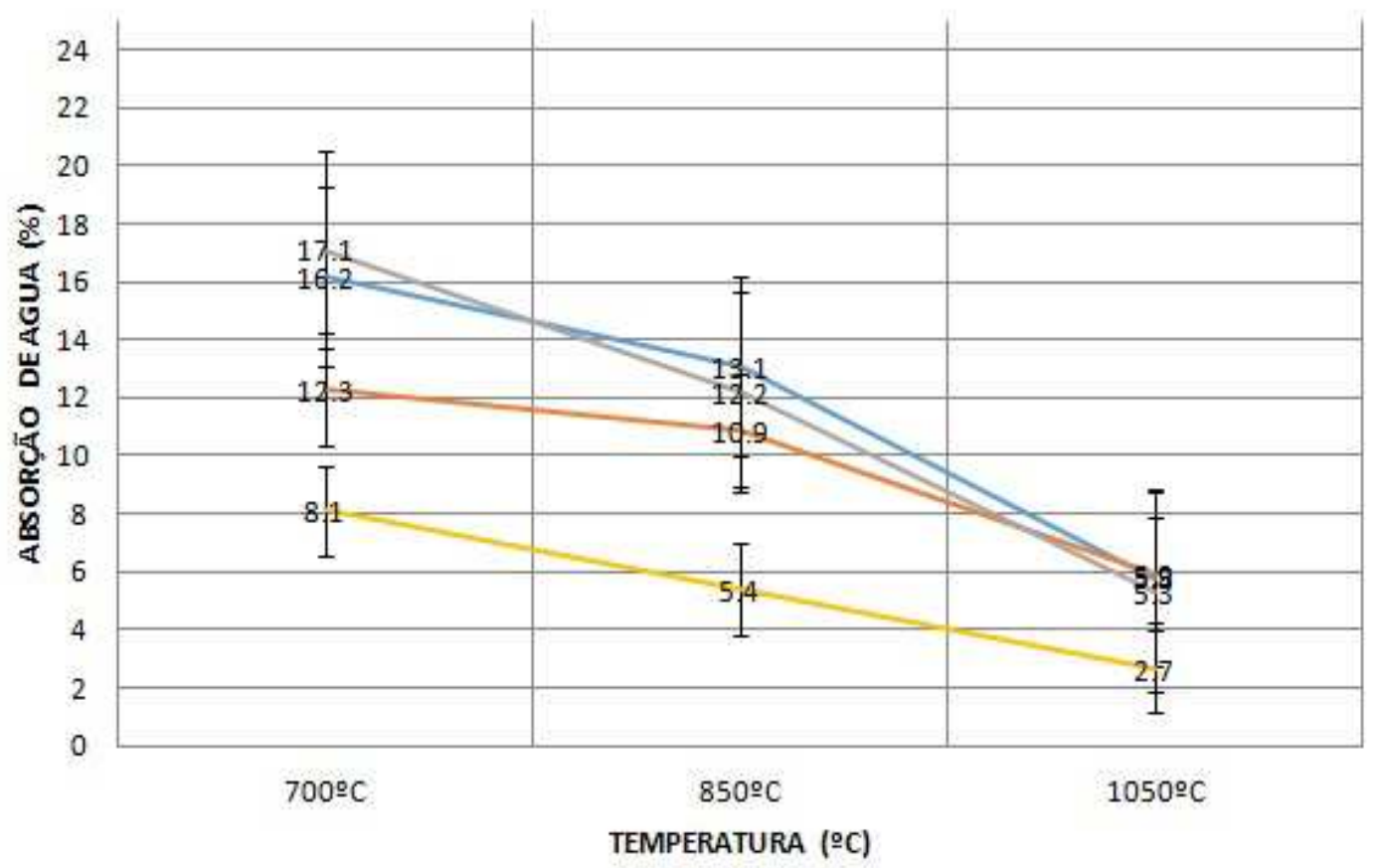

$$
-\mathrm{AV}-\mathrm{BPps}-\mathrm{AB1}-\mathrm{AB2}
$$

Figura 2. Absorção de água (\%) após queima 
A figura 2 apresenta os valores de absorção de água das amostras para três diferentes temperaturas de queima De acordo com a figura 2, notou-se uma redução da absorção de água. Segundo Callister [9], isso está relacionado com o grau de vitrificação, que aumenta com a temperatura de sinterização e diminui a absorção de água devido a redução da porosidade. Esse processo de vitrificação ocorre pela formação de uma fase líquida, dentro da peça que preenche os poros existentes, aumentando o coalescimento das partículas não fundidas. Segundo a Pinheiro [10], que indica que a absorção de água tem que ser inferior a $25 \%$ para os corpos-deprova de argilas para produção de blocos cerâmicos, as amostras estudadas possuem valores inclusos no indicado.

A figura 3 mostra o resultado para perda ao fogo para as amostras em três temperaturas de queima distintas.

\section{Perda ao Fogo}

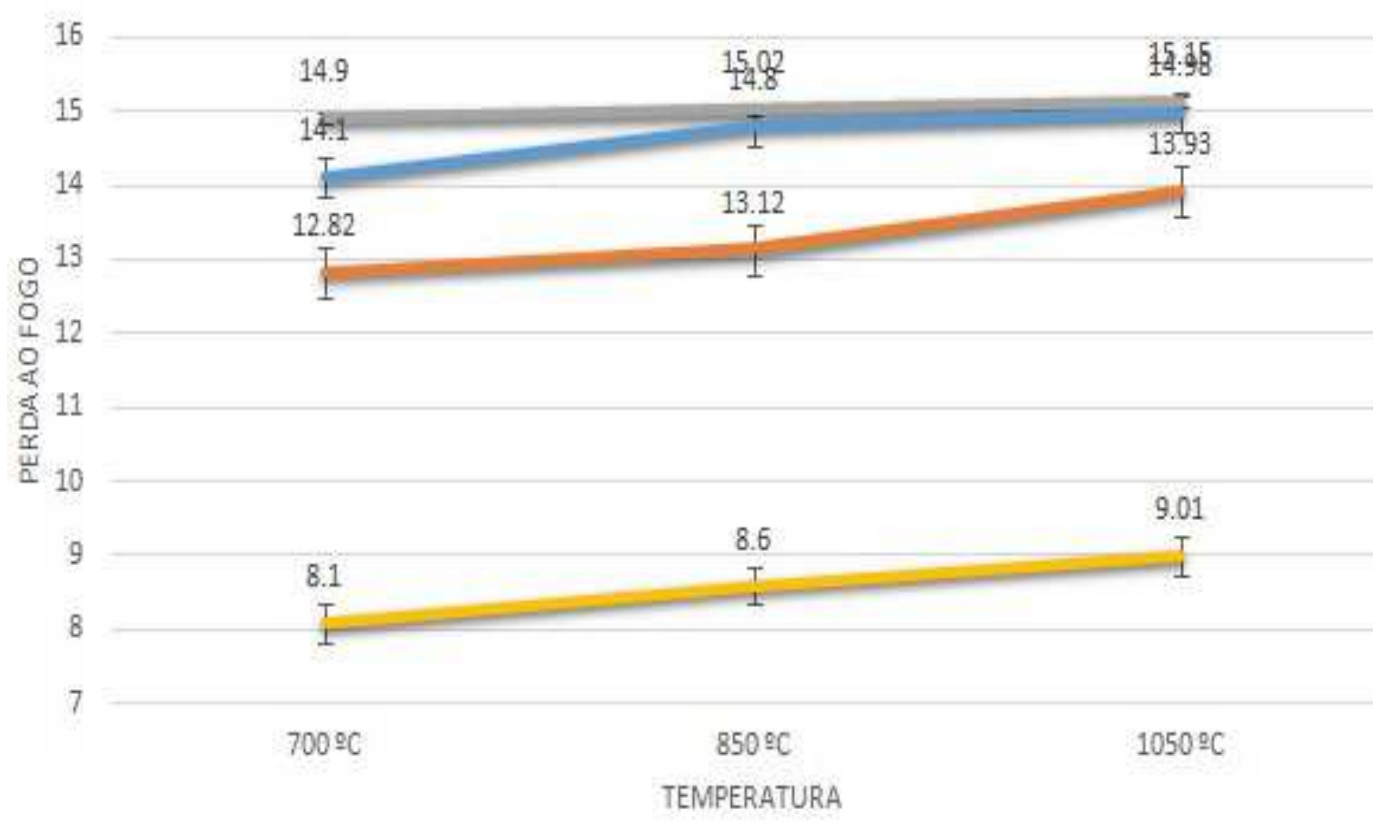

$\longrightarrow \mathrm{AV}=\mathrm{BPps}=\mathrm{AB1}=\mathrm{AB2}$

Figura 3. Gráfico Perda ao fogo

Analisando os dados da figura 3, pôde-se perceber que a perda ao fogo aumentou com o aumento da temperatura de queima. Apesar desse aumento, a variação do parâmetro não foi grande. As argilas com altas plasticidades obtiveram maiores valores de perda ao fogo. Estas, normalmente, possuem grande quantidade de matéria orgânica e outros componentes, os quais no processo de sinterização são eliminados.

A figura 4 mostra os valores de tensão de ruptura à flexão dos corpos de prova. 


\section{Tensão de Ruptura à flexão}

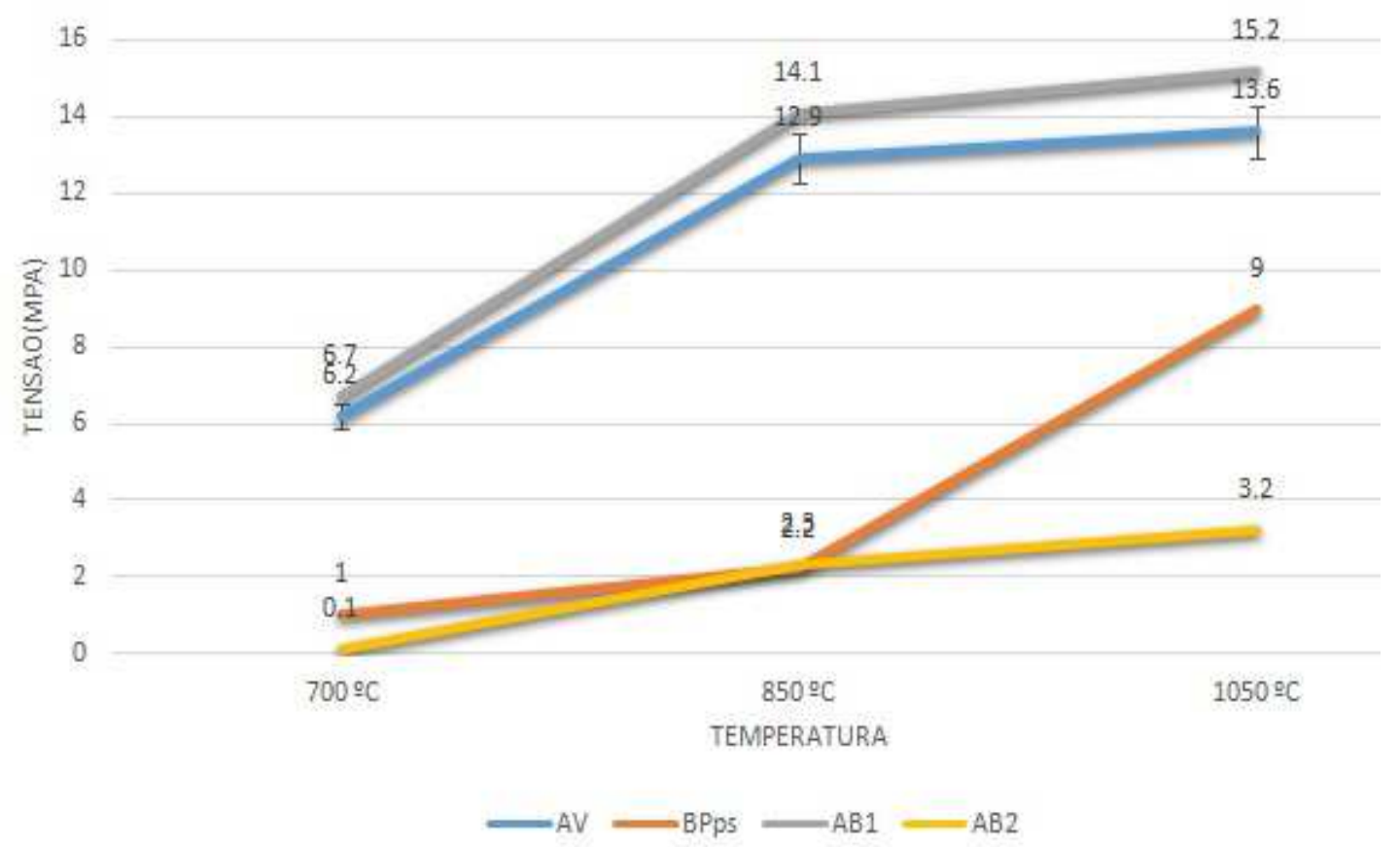

Figura 4. Tensão de ruptura por flexão

$\mathrm{Na}$ figura 4 pode-se perceber que a tensão de ruptura aumentou com o aumento da temperatura, porém o aumento de temperatura não foi suficiente para obter elevadas tensões. Verifica-se que a amostra $A B 1$ apresenta os maiores valores de tensão em todas as temperaturas de queima.

Além disso, a resistência mecânica aumenta de acordo com redução da absorção de água que se dá pela redução da porosidade aberta com o aumento da temperatura de queima. Segundo Pinheiro [10], isto indica que a principal causa para o aumento da resistência mecânica em cerâmica vermelha é a redução da porosidade aberta no interior da peça cerâmica, de forma que, dependendo do tipo de produto de cerâmica vermelha a ser processado, há necessidade do controle do nível de porosidade aberta.

A desvantagem da porosidade aberta sobre a resistência mecânica está fundamentalmente relacionada aos seguintes fatores: i) os poros diminuem a área da seção cruzada na qual a carga é aplicada; e ii) os poros atuam como concentradores de tensão, de acordo com Pinheiro [10].

\section{CONCLUSÃO}

Foram estudadas 4 amostras de argilas fornecidas por uma indústria de tijolos cerâmicos (Cerâmica Pé Seco) da Região do Cariri-CE. As amostras AV, BPps e AB1 apresentaram plasticidade alta e a amostras designada por AB2 apresentou plasticidade mediana. Observando, todos os gráficos, houve aumentos crescentes das propriedades físico-mecânicas de ruptura por flexão, perda ao fogo e retração linear com o aumento da temperatura de queima e houve redução da absorção de água com o aumento da temperatura de queima. Portanto, nota-se que houve uma relação coerente entre os valores obtidos, e a faixa de valores recomendados pela literatura Souza [11], Macedo [6] e Barba [12]. Foi possível conhecer as características das argilas utilizadas pelas fábricas da região, de forma que será 
possível reformular ou melhorar massas já existentes a fim de tornar os produtos fabricados pelas empresas dentro dos padrões estabelecidos por Normas Técnicas.

\section{Agradecimentos}

Os autores agradecem a FUNCAP pela concessão de bolsas de IC e auxílio financeiro, processo BP1-0067-00098.01.03/12 e ao Departamento de Engenharia de Materiais da Universidade Federal de Campina Grande - UFCG pelos muitos ensaios realizados pelo Departamento contribuindo de forma significativa para o andamento da pesquisa.

\section{REFERÊNCIAS}

1 FIEC: Disponível em HTTP://www.fiec.org.br Acesso em 08/08/2012.

2 MEHISUFC: Disponível em <HTTP://www.mehisufc.blogspot.com.br> Acesso em: 08/08/2012.

3 ABNT (Associação Brasileira de Normas Técnicas). NBR 6459: Determinação do limite de liquidez-método de ensaio. Rio de Janeiro: ABNT, 1984.

4 ABNT (Associação Brasileira de Normas Técnicas). NBR 7180: Determinação do limite de plasticidade- método de ensaio. Rio de Janeiro: ABNT, 1984.

5 Macedo, RS: Estudo das matérias-primas e tijolos furados produzidos no Estado da Paraíba [Diss. Mestrado] DEQ-CCT-UFPB;1997.

6 Macedo RS, Menezes RR, Neves GA, Ferreira HC. Estudo de argilas usadas em cerâmica vermelha.2008

7 Macedo, RS. Estudo comparativo entre massas cerâmicas industriais e aditivadas para uso em blocos cerâmicos. [Tese de doutorado em Engenharia de Processos]. Campina Grande: CCT/UFCG;2005.

8 Cartaxo AS, Suassuna PM, Martins FMP, Prado ACA, Brasileiro MI. Caracterização de argilas utilizadas na indústria de cerâmica vermelha na região do Cariri - Ceará - parte II.In: Encontros Universitários- UFCA; 2013; Ceará, Brasil.

9 Callister Jr W D, Rethwisch D G. Ciência e Engenharia de Materiais: Uma Introdução.8.ed. Rio de Janeiro :LTC; 2013.

10 Pinheiros B. C. A., Holanda J. N. F. Efeito da temperatura de queima em algumas propriedades mecânicas de cerâmica vermelha. Cerâmica 56 (2010) 237-243.

11 Santos PS, Ciência e Tecnologia de Argilas v. I e II, São Paulo: Edgard Blücher;1992.

12 Barbas A, Beltràn V, Feliu C, García J, Ginés F, Sànchez E, Sanz V. Materias primas para la fabricación de soportes de baldosas Cerámicas. ITC, 1a․ Ed. Castellón, Espaňa. 1977. 